THE JOURNAL OF THE BRITISH MEDICAL ASSOCIATION.

LONDON: SATURDAY, JANUARY 1sT, 1921.

\section{A ON THE}
DIAGNOSTIC SIGNIFICANCE OF ABDO- MINAL PAIN IN CHILDHOOD.*
BY

ROBERT HUTCHISON, M.D., F.R.C.P.,

PHÝSICIAN TO THE LONDON HOBPITAL, AND TO THE HOSPITAL FOB GICK CHILDREN, GREAT ORMOND STREET.

AвDóminal pain in a child must always bo a source of anxiety to the doctor. It may mean so little or so much. It may be due to nothing worse than an attack of acute indigestion set up by a green apple; or it may indicate an attack of acute peritonitis set up by a green and gangrenous appendix. It is a matter, therefore, which craves wary walking in diagnosis, for a mistake may bo fatal, and between one's anxiety not to overlook a serious cause and one's natural reluctance to alarm the parents anduly it is often difficult to steer a proper course. Our difficulty in these cases is increased by the fact that pain may be the sole symptom of abdomiral disease, and the little patient may be unable to help us, as an adult can, by describing its exact situation; character, and so forth, which are often so signiticant for diagnosis. It seemed, therefore, that we might profitably employ our time this afternoon by con. sidering together the chief causes of abdominal pain in childhood, with a view to onabling us, when we meet such cases, to malke a diagnosis by the method of exclusion if no other is available.

\section{Extra-abdominal Causes of Pain.}

At the outset it is well to remenaber that pain felt in the abdomen is not neccssarily being caused there. In children, who localize their sensations badly, these extraabdominal causes of pain are specially apt to lead to error. We may divide them according as the cause has its seat (1) in the abdominal wall, using that term in its widest sense, or (2) in the thorax.

\section{Causes in the Abdominal Wall.}

Spinal Caries.-Of causes situated in the abdominal wall this is one of the commonest. The pain in such cases is due, of course, to pressure on the posterior nerve roots, and is usually referred along the lower intercostal nerves to the epigastrium. It may come on quite early in the disease before any gross spinal deformity has shown itself, and the child will be brought to you under the belief that he is suffering from some abdominal trouble. It is well, therefore, to make it a rule carefully to examine the back in all cases of chronic epigastric pain in children. Slight prominence of one or more vertebral spines in the lower dorsal region can usually be detected, with tenderness on percussion over them and some stiffness on stooping. If in doubt, one can call in the help of the radiographer.

Lateral curvature in its more pronounced degrees is a similar source of error, but is less likely to be overlooked.

Rheumatism, or perhaps one should call it fibrositis, affecting the abdominal muscles, may easily simulate pain of intra-abdominal origin, and, like all rheumatic manifestätions, is relatirely common in childlyood. It may be

\footnotetext{
* Delivered before the South Midland Branch on July 8th, 1920.
}

met with either at the insertion of the muscles into the ribs or iliac crests or in the aponeurotic sheaths of the muscles themselves. The well-known "stitch in the side" which is common in children may, perhaps, be of this nature, but it is also met with in a chronic and protracted form. Fibrositis may be distinguished by the fact that the pain comes on when the affected muscle is thrown into action, as, for example, when the patient tries to sit up in bed without using the hands; there is often quite acute tenderness at certain parts of the abdominal wall, especially when the muscle is contracted, and if the abdomen is palpated in the ordinary way this may be mistaken for tenderness of an underlying organ. This error may be avoided by noting that tenderness is also elicited when the abdominal wall is grasped or compressed laterally. This form of pain is commonest in children of school age, and often follows hard exercise, and if the muscles of the right lower quadrant are involved appendicitis may be simu.

lated. One sometimes wonders whether cases of so-called "rheumatic appendicitis" cured by salicylates are not really of this nature.

Herniae through the abdominal wall are not such a common cause of obscure chronic abdominal pain in the child as they are in the adult; but in the form of omental herniae especially they should always be thought of, and so should the possibility of an undescended testis.

Hip disease I have sometimes known to lead to error; not so much tuberculous hip disease as an acute inflam. matory condition in or near the joint. This may cause pain referred to the lower part of the abdomen; there may be fever and the child may lie with the legs drawn up; and when the right hip is affected simulation of appen. dicitis may be fairly close. The limitation of movement in the joint which careful examination reveals ought, however, to keep one right.

Herpes zoster is the last of the causes in the abominal wall which $I$ shall mention. Pain in this affection may precede the appearance of the eruption by some hours or even days, and be of consider. able severity; and I have known more than one instance in which it led to a diagnosis of acute abdominal disease. It can be distinguished by the fact that there is a band of superficial hyperaesthesia in the distribution of the affected nerve, that there is also severe pain behind, near the vertebral spines, and that deep tenderness on palpation or involuntary rigidity are absent. All doubts are dispelled before long by the appearance of the eruption.

\section{Thoracic Causes.}

The possibility of abdominal disease being simulated by acute intrathoracic conditions has been well recognized ever since attention was first directed to it by the late Mr. Barnard some years ago. Yet mistakes are still easy to make. The commonest form of error is to diagnose a case of pneumonia occurring at the right base as one of appendicitis. If the patient is a child, such an erro: is specially excusable, for in the child, more even than in the adult, the physical signs of a pneumonia may be entirely absent for some time after the disease has begun. Further: more, vomiting is a very constant and conspicuous fenture of early pneumonia in childhood, and helps still further to gimulate the picture of abdominal disease. The abdominal pain in these cases is due, as you all know, to involvement of the lower intercostal nerves as they pass through the diaphragm, and in part also it may be a "referred pain." There is reason to believe that it only occurs when the diaphragmatic pleura is affected. Be this as it may, the 
combination of an acute onset, with fever, vomiting, pain referred to the lower abdomen, and some abdominal rigidity, coupled with an absence of the usual signs of pneumonia, may be deceptive in the highest degree. In attempting to make a diagnosis in such a case you will look for an alteration in the pulse-respiration ratio, though it is well to remember that the respiration is not always hurried at the onset of pneumonia in a child. You will note that the abdominal tenderness is superficial, and that there is no sign of pain on moderately firm deep palpation. You will also ascertain the presence or absence of tenderness in the recto-vesical pouch on examination by the rectum, although perhaps it is true to say that in the child this is more easily said than done. You will remember, also, that the higher the temperature the more likely is it that the case is one of pneumonia. In some cases you must remain in doubt, and then it is wise to stay your band, and in a few hours, perhaps, the appearance of a pleuritic rub or a patch of dullness will make clear the nature of the disease.

Pericarditis, but apparently only when the diaphragm. atic surface is involved, may also simulate abdominal disease, although it is much less common as a source of error than pleurisy or pneumonia. I remember a case of the sort which made a strong impression upon me at the time. The patient was a little boy, who was admitted to hospital under the belief that he had acute appendicitis. He looked very ill, lay with the linees drawn up and the abdomen rigid, complaining of pain which he referred to the hypogastrium. There was moderate fever, but an entire absence of other signs. I have forgotten whether he vomited. He was kept under observation for a few hours, and it was decided that if there were no more positive indications by the evening the abdomen should be opened. Just before the time agreed upon for this, however, a loud pericardial rub became audible, and the case subsequently ran the course of an ordinary rheumatic pericarditis.

\section{Intra-abdominal Causes of Pain.}

Let us now pass on to consider the far more frequent cases in which the cause of pain is situated in the abdomen itself. We may divide these for the sake of convenience into (1) cases of sudden or catastrophic pain, and (2) cases of chronic or recurrent pain.

\section{Sudden Catastroplic Pain.}

By the "catastrophic" cases I mean those in which the pain sets in suddenly-"out of the blue" so to speakand is of great intensity. They are the cases often spoken of as "abdominal catastrophes," and include many examples of what are known in surgical slang as "the acute abdomen." They are for the most part of surgical rather than medical interest, and I shall not say much about them except to point out as far as one can those in which immediate laparotomy is indicated.

At the outset it may be well to remind you that the possible causes of an abdominal catastrophe are far fewer in the child than in the adult. Children do not suffer from perforated gastric or duodenal ulcer, for instance, or from acute pancreatitis, and I can recall only one case of biliary colic in a child. The possibilities which one has chiefly to consider when confronted with a case of severe abdominal pain of sudden onset at this age are acute indigestion, appendicitis, and some form of acute intestinal obstruction, of which that due to intussusception is specially frequent in the child. Amongst the rarer causes one might perhaps mention abdominal or Henoch's purpura. Renal colic, whicli may also have to be considered, I shall have occasion to mention later on.

The immediate practical diagnostic problem in such a case is to eliminate acute indigestion. This is not always easy. The pain of acute indigestion may set in suddenly, may be of great severity, and may be attended by fever and considerable distress. Here is an example. A boy of 7 , whilst convalescing from a mild attack of whooping. cougl, was attacked by sudden abdominal pain of considerable severity, and in an hour or two his temperature had run up to 104. He was restless and distressed, and begged that "something should be given him to relieve his pain." In view of the recent whooping-cough various diagnostic possibilities presented themselves, but soon one's doubts were solved by the copious vomiting of a quantity of undigested food, shortly after which he broke into a profuse sweat, and the temperature came down with a run. If in doubt about such a case, the best course is not to pooh-pooh the whole affair as a mere stomach-ache and to give a dose of castor oil-still less an opiate-but to hold one's hand and wait. Meanwhile, there is no harm in giving an enema, and perhaps a mild emetic, and applying heat to the abdomen for relief of the pain.

The possibility of appendicitis is what will give you the most anxiety in these acute cases of pain. I shall not go into the diagnostic criteria in this matter in any detail, as they are much the same as hold good in the case of the adult; but $I$ would only remind you that pain is the earliest symptom in appendicitis, that it is usually experienced first in the epigastrium, and only later settles into the right iliac fossa, and that it is rarely of great severity except in a very norvous child. Vomiting nearly always occurs, but it follows the pain and does not persist, as it does, for example, in cyclical vomiting; and although more or less fever is always present at some stage of the attack, it is rarely great in degree. In looking for muscular rigidity in children, light palpation is more important even than in the case of the adult.

Acute intestinal obstruction is nearly always attended by pain, which may be very severe, but I have seen cases of intussusception in which, at the outset at least, pain was entirely absent; probably they were cases in which there was an unusually long mesentery. The classical șigns and symptoms of obstruction will be present in the child as in the adult, but it is well to remember that, owing to the tendency of the child to develop a temperature on slight provocation, some fever may be present even in purely obstructive cases, especially, perhaps, in intus susception. In the examination of these cases an anaesthetic is often of great help. It saved the situation in the case of a little boy whom I saw not long ago, who had been seized two days previously with severe abdominal pain. Other symptoms of intussusception were absent, but the abdomen was rather rigid and difficult to examine. He did not seem at all ill, and one was inclined to regard it as a case of colic, but under a whiff of chloroform the abdominal walls immediately relaxed, and a typical sausage-shaped tumour could then be felt running across the abdomen.

I have mentioned abdominal purpura as a possible cause of sudden acute pain. You will not expect to meet with this often, but as it is usually attended by haemorrhage from the bowel, it may simulate intussusception rather closely. A mistake may be avoided by careful examination for purpuric blutches in the skin, which are often to be found in such cases.

\section{Chronic or Recurrent Pain.}

When an adult complains of chronic pain in the abdomen the first organ one thinks of is the stomach. In the child, however, the stomach is rarely at fault in such circum. stances. Children, I need hardly remind you, do not suffer from organic disease of the stomach, such as ulcer or carcinoma, and in them chronic or recurring abdominal pain usually has its seat of origin in the intestine. It is true that ordinary indigestion may cause some pain, probably from distension of the stomach with gas, but it is rarely severe in degree-rather a mere discomfort-and its definite relation to meals and its relief after the belching up of wind will usually make the nature of the case plain The intestinal cases are, as I have said, far commoner, and we may divide them for convenience into those due to $(a)$ ordinary colic, (b) "umbilical" colic, the meaning of which is to be explained immediately, (c) enterospasm, and $(d)$ chronic obstruction.

(a) Ordinary colic is, of course, the commonest cause of abdominal pain in little babies, but it is met with also often enough in older children, and may contribute to the pain in those cases of acute indigestion of which I have already spoken. In the chronic or recurrent form it is more apt to appear as the variety known as "umbilical" colic, of which I shall speal presently. In whatever form it shows itself it is characteristic of colic that the pain occurs in spasms, that it is relieved by firm pressurediffering in this profoundly from the pain of appendicitis, for instance-and, what is of great diagnostic value if ${ }^{i}$ it is observed, that it is relieved, temporarily at least, by the expulsion of flatus from the bowel.

(b) The term " umbilical" colic was introduced by Professor Moro to designate a common group of cases, met with in children of school age, in which the patient 
complains of frequently recurring abdominal pain, which is always referied to the situation of the umbilicus. The pain may come on suddenly at any time in the day, but sometimes quite definitely after or during a meal. It may be serere whilst it lasts, even doubling the child up, and may be attended by sudden pallor. Vomiting is rare. The attack may last for only a moment or two or for a few hours, and there is sometimes a tendency for attacles to exhibit periodicity. As I have said, these cases are by no means uncommon, and every one who has done much outpatient work amongst children must be familiar with thern, but their real nature is obscure. There are usually no objective signs of disease to be made out, and Moro was of opinion that the condition is a pure neurosis. I can hardly think this likely, and it seems more probable that we are dealing in these cases with a genuine colic in the large intestiue occurring in rather constipated nervous children in whom perhaps the "gastro.colic" reflex is abuormally active-a condition closely alin to lienteric diarrhoea. () the treatment of these cases, which is troublesome enough, there is no time to speak to-day, but their chief importance arises from the fear that in them one may really be dealing with "chronic appendicitis," but on that subject I shall have something to say in a moment.

(c) Enterospasm as a cause of abdominal pain is met with in clildren who are the subject of muco-membranous colitis. 'This is not infrequent in clildhood, and when spasm of part of the colon occur's very serere pain may be produced. The contracted bowel may sometimes be felt, usually in the left iliac fossa, and the presence of mucus and membranes in the stools should malre the diagnosis clear. It is worth remembering that muco-mem. branous colitis in clildren is sounetimes attended by pro. longed fever of considerable degree, and when attacks of enterospasm are superadded mistakes in diagnosis may easily occur.

(d) Chronic intestinal obstruction as a cause of abdominal pain is rare in childhood, and when it occurs is usually due either to compression of the bowel by a band, or a persistent Meckel's diverticulum, or to adhesions the result of old tuberculous peritonitis. Tho pain resembles that of colic in its nature, but there is usually some meteorism present, and visible coils of intestine may be seen. 'There is not necessarily any vomiting. The use of the $x$ rays may help in the diagnosis if one is in doubt. The most difficult cases are those due to chronic intussusception, and in at least two instances of that condition I have known the true cause of the pain overlooked, even though the patient was for a long time under observation in hospital.

Appendicular Pain,

I now come to the most anxious cases of all-those, namely, in which the question arises whether a chronic or fecurrent pain has its seat in a diseased appendix. There are some, I believe, who deny the existence of chronic appendicitis in childhood altogether. I think I have heard a surgeon say that a child either has acute appendicitis or the symptoms are not due to the appendix at all. Most of you will probably agree that this is an extreme vicw, but at the same time I am sure that one ought to be extremely cautious in diagnosing chronic appendicitis in children, especially when the pain is confiued to the right side of the abdomen. On the other hand, it is probably nearer the truth to say that disease in the appendix in the child is never chronic from the beginning, there is alvays a preceding acute or subacute attack. In making a diagnosis, therefore, a history of such attaclis should be inquired into with great care. They will usually be described as "bilious attacks," but if they were attended by pain, some vomiting, and fever, and were bad enough on any occasion to confine the child to bad, one should be very suspicious. Physical examination in cases of clironic or relapsing appendicitis between attacks may be entirely negative, and $I$ do not think that the use of $x$ rays affords much help. One must often be in doubt between chronic appendicitis and " umbilical colic," but if there is a clear history of "bilious attacks," and if the parents, as so often happens, are worried about the state of the appendix, then $I$ think it is best to advise exploration, although it is unwise to guarantee any result from the operation other than the relief of the parental mind.

Worms are often believed by parents to be a cause of abdominal pain in childhood, but my own experience would not bear this out. Round worms are those which would be most likely to produce the symptoms, for they are sometimes numerous enough even to produce intestinal obstruction. A vermifuge will soon settle the diagnosis.

Enlarged glands, on the other hand, are, I believe, a much commoner cause of abdominal pain in children than is generally realized. I do not mean necessarily tuberculous glands, but a simple enlargement of the glands at the lower end of the mesenterv: These often become infected in cases of appendicitis in childıen, just as the glands at the angles of the jaw do in tonsillitis. I saw a very striking example of this not long ago in the case of a boy who was suddenly attacked with pain, vorniting, and fever. He presented the signs of appendicitis, but there was a curious tumour about the size of a walnut to be felt in the right iliac fossa which was certainly not the appendix. At operation it proved to be a mass of acutely inflamed glands, the appendix being also inflamed and its mucous membrane ulcerated. There is often no listory of any acute disease in these cases of chronic enlargement of glands, though no doubt they must have been infected from the caecum or appendix; but, once enlarged, they are apt to cause pain in the right lower quadrant, possibly by dragging upon or kinking the bowel. At all events thicy are often the only thing found wrong in children on whom an exploratory operation has been performed for suspected chronic appendicitis, and their removal is usually followed by disappearance of the attaclis of pain.

\section{Causes in the Urinary Tract.}

Affections of the urinary tract are a frequent and often overlooked cause of abdominal pain in early life, just as they are in the adult, although some conditions which are relatively common in grown-up persons are rare in the child. Movable kiclney, for example, though it is occa. sionally met with in children, need hardly be thought of as a cause of pain. Attacks of true renal colic also are not often exlibited in the child, though gravel is perlsaps a not uncommon cause of pain in babies. On the otlier hand, there are two conditions which are certainly more frequently sources of abdominal pain in the child than is generally realized: one is kinking of the ureter and the other is ureteric calculus.

Kinking of the ureter results, as you know, from a congenital abnormality in the distribution of the renal blood vessels. As a rule it does not produce symptoms until early adult life, but I believe that it would be diagnosed oftener in the clild if it were looked for. It is one of the causes of so-called "bilious attacks." I had once a very striking example of this in the case of a boy of 15, who was alleged to have suffered gince his early childhood from attacks of abdominal pain and vomiting which recurred every few weeks with great regularity. They had been diagnosed as "bilious attacks." I happened to see him in an attack. He referred the pain to the left loin, and an enlarged and slightly tender lidney could easily be felt on palpation. Surgical investigation establislred the presence of kinking of the ureter, and a greatly disorganized kidney was subsequently removed. 'These cases are deceptive because of the regular periodicity of the pain and the entire absence of any urinary symptoms.

Ureteric Calculus.-Just as the symptoms of a kinked ureter are apt to be diagnosed as "bilious attacks" so the symptoms of a ureteric calculus, when it occurs in the right side, are usually attributed to "chronic appendix mischief," and indeed the simulation may be very close. There may be a history of attacks of right-sided spasmodic pain; there may be a rise of temperature and tenderness over the ureter (which is very ciose to McBurney's poini), and urinary symptoms may be absent. The moral is that a radiograph of the ureteric region should always be taken before an operation is performed in quest of a supposed diseased appendix.

In the male urethral obstruction as a result of phimosis or a narrow meatus may cause attacks of hypogastric pain from over-distension of the bladder, but the association between the pain and the difficulty of micturition is usually obvious, and the vesical tumout easily made out. In girls, on the other liand, one luas sometimes to think of pelvic causes such as salpingitis, but I mention these rather for the sake of completeness than because I regard them as common causes of abdominal pain in childhood. 